\title{
CRESCIMENTO E NODULAÇÃO NATURAL DE FEIJÃO-CAUPI EM SOLOS DE MINERAÇÃO DE CHUMBO ADUBADOS COM RESÍDUO DE SISAL ${ }^{1}$
}

\author{
Djalma Silva Pereira ${ }^{2 *}$, Rafaela Simão Abrahão Nóbrega ${ }^{3}$, José Ferreira Lustosa Filho ${ }^{4}$, Altemar dos Santos \\ Dias $^{5}$, Gilca dos Santos Veloso ${ }^{5}$, Elves de Almeida Souza ${ }^{6}$
}

\begin{abstract}
RESUMO - O estudo da nodulação natural do feijão-caupi (Vigna unguiculata L. Walp) em solos contaminados com metais é importante para identificar grupos de bactérias tolerantes que o nodulam para estudos futuros visando a reabilitação desses solos. Objetivou-se avaliar o efeito das proporções de resíduo de sisal (Agave sisalana) em solo de mineração de chumbo no desenvolvimento inicial e na nodulação natural do feijão-caupi. Os tratamentos foram dispostos em delineamento experimental inteiramente casualizado sob arranjo fatorial 4 x 3 (quatro proporções de sisal e três solos coletados em distintas distâncias da antiga sede da Companhia Brasileira de Chumbo - COBRAC, localizada em Santo Amaro, BA), com cinco repetições. As variáveis analisadas no florescimento da cultura foram: clorofila total $(a+b)$, número de nódulos, área foliar, massa seca da parte aérea, massa seca da raiz e massa seca total. A nodulação e as variáveis de crescimento das plantas variaram de acordo com as proporções do resíduo de sisal. Na proporção média de 80:30 de solo:sisal houve o máximo número de nódulos nas plantas de feijão-caupi cultivado em solos de mineração de chumbo. A adição do resíduo de sisal proporcionou o aumento no índice de clorofila e na massa seca total nas plantas de feijão-caupi.
\end{abstract}

Palavras chave: fixação biológica de nitrogênio, resíduo de Agave sisalana, Vigna unguiculata L, Walp.

\section{GROWTH AND NATURAL NODULATION OF COWPEA IN LEAD MINING SOIL COMPOSTED WITH SISAL RESIDUE}

\begin{abstract}
The study of the nodulation of Cowpea (Vigna unguiculata L. Walp) in soils contaminated with metals is important to identify groups of bacteria tolerant that the nodulam for future studies aimed at rehabilitation of these soils. This work aimed to evaluate the effect of proportion of residue of sisal (Agave sisalana) in lead mining soil in the initial development and nodulation of Cowpea. The treatments were displayed in a complete randomized factorial design of $4 \times 3$ (four proportions of sisal and three soils collected at different distances from the former headquarters of the Brazilian Company of lead-COBRAC, located in Santo Amaro, Bahia), with five repetitions. The variables analyzed in the flowering of culture were: chlorophyll total (a $+b)$, number of nodules, leaf area, shoot dry matter, root dry matter and total dry matter. Nodulation and plant growth variables varied according to the proportions of the sisal residue. The average proportion of 80:30 of soil:sisal have provided the maximum number of nodules in the Cowpea plants grown in lead mining soil. The addition of the sisal residue have provided the increase in the index of total dry mass and chlorophyll in plants of Cowpea.
\end{abstract}

Keywords: biological fixation of nitrogen, gunshot residue of Agave sisalana, Vigna unguiculata L, Walp.

\footnotetext{
${ }^{1}$ Parte do trabalho de conclusão de curso do primeiro autor, apresentada ao colegiado do curso de Graduação em Tecnologia em Agroecologia da Universidade Federal do Recôncavo da Bahia (UFRB).

${ }^{2}$ Mestre em Agroecologia pela Universidade Federal de Viçosa(UFV), Viçosa, MG, Brasil. Bolsista FAPEMIG. E-mail: djalma.pereira@ufv.br. Autor para correspondência.

${ }^{3}$ Professora do Centro de Ciências Agrárias, Ambientais e Biológicas da UFRB.

${ }^{4}$ Mestre em Agronomia - Solos e Nutrição de Plantas pela Universidade Federal do Piauí (UFPI).

${ }^{5}$ Graduados em Agroecologia pela UFRB.

${ }^{6}$ Doutor em Engenharia Agrícola pela UFRB.
} 


\section{INTRODUÇÃO}

O feijão-caupi é uma planta utilizada como plantaisca para a captura de rizóbios presentes no solo devido a sua alta capacidade de nodulação com diferentes gêneros de bactérias fixadoras do nitrogênio - $\mathrm{N}_{2}$ atmosférico (BNL) tais como Rhizobium (Jaramillo et al., 2013), Mesorhizobium (Moreira, 2008), Microvirga (Marinho et al., 2014), Bulkholderia (Moreira, 2008), Brevibacillus (Costa et al., 2013), Sinorhizobium (Moreira, 2008), Acinetobacter (Marra et al., 2012), Azorhizobium (Moreira, 2008), Ralstonia (Sarr et al., 2009) $e$ Allorhizobium (Moreira, 2008).

A fixação biológica de nitrogênio (FBN) é realizada a partir da simbiose das espécies leguminosas com bactérias fixadoras, que formam nódulos em suas raízes, capazes de absorverem o nitrogênio da atmosfera convertendo em amônia para posterior conversão em aminoácidos para nutrição vegetal.

A contaminação do solo por metais pesados pode causar transformações nas comunidades microbianas do solo (Trannin et al., 2001). Desta forma, torna-se relevante a utilização de bactérias fixadoras como plantaisca de BNL para avaliar a nodulação natural do feijãocaupi em solos com altas concentrações de metais a fim de identificar possíveis grupos de bactérias tolerantes que o nodulam para estudos futuros visando reabilitação de solos contaminados em projetos de fitorremediação.

Em solos contaminados com metais pesados, o cultivo do feijão-caupi visa encontrar bactérias tolerantes a esses metais, para posterior produção de inoculantes para plantas utilizadas na reabilitação dessas áreas.

Os metais são considerados uma das principais fontes de poluições de ecossistemas naturais, podendo estar presentes no solo naturalmente, resultante do intemperismo ou em decorrência das atividades antrópicas (Kede et al., 2008; Lima et al., 2013). Dentre os metais pesados, o chumbo $(\mathrm{Pb})$ é amplamente utilizado na indústria metalúrgica, gerando rejeitos ricos no metal, que se destinados de forma incorreta podem impactar negativamente os ecossistemas. Este metal quando presente nas camadas superficiais do solo pode estar facilmente disponível para as plantas (Magna et al., 2013).

No município de Santo Amaro, Recôncavo da Bahia, foi constatada alta concentração de $\mathrm{Pb}$ em parte da população, no solo e nos sedimentos do Rio Subaé, devido às atividades metalúrgicas da Companhia Brasileira de Chumbo (COBRAC), a qual instalou-se na cidade na metade do século XX (Kede et al., 2008; Magna et al., 2013).

Assunção (2012) constatou concentração de 3148,4 $\mathrm{mg} \mathrm{kg}^{-1} \mathrm{de} \mathrm{Pb}$ no solo nas proximidades da COBRAC. Magna et al. (2013) constataram quantidades elevadas de $\mathrm{Pb}$ e cádmio em várias espécies vegetais cultivadas em quintais de moradores neste município.

Dentre as técnicas utilizadas para remediação de áreas contaminadas com metais está o uso de materiais orgânicos. A matéria orgânica participa ativamente na imobilização dos metais principalmente pela presença dos grupamentos carboxílicos e fenólicos, sendo esse comportamento capaz de gerar sítios de adsorção, que torna o metal indisponível para as plantas através de ligações iônicas e, ou quelação (Martins et al., 2011). Desta forma, o uso de material orgânico torna-se importante como uma alternativa mitigadora da remediação de metais pesados no solo.

O resíduo de sisal (Agave sisalana) pode ser utilizado como fonte de matéria orgânica para compor substratos de mudas. O sisal possui destaque socioeconômico para a região semiárida da Bahia, visto que o resíduo oriundo do processo de extração das fibras das plantas muitas vezes é descartado de forma inadequada pelos agricultores (Martin et al., 2009; Santos et al., 2010). Pressupõe que o feijão-caupi cultivado com solos de mineração de chumbo acrescido de resíduo de sisal possa estabelecer nodulação com bactérias nativas do solo.

Diante do exposto, objetivou-se neste estudo avaliar o efeito das proporções de resíduo de sisal (Agave sisalana) em solo de mineração de $\mathrm{Pb}$ no desenvolvimento inicial e na nodulação natural do feijãocaupi (Vigna unguiculata L.).

\section{MATERIALE MÉTODOS}

O experimento foi conduzido em viveiro, no Campus de Ciências Agrárias, Ambientais e Biológicas (CCAAB) da Universidade Federal do Recôncavo da Bahia (UFRB), no município de Cruz das Almas-BA. O município está geograficamente situado nas coordenadas: latitude $12^{\circ} 40^{\prime} 19^{\prime \prime} \mathrm{S}$ e longitude $39^{\circ} 06^{\prime} 23^{\prime \prime} \mathrm{W}$. A região possui um clima do tipo Am úmido a subúmido, com temperatura média de $24,1^{\circ} \mathrm{C}$, precipitação média anual de $1.170 \mathrm{~mm}$ e umidade relativa do ar de $80 \%$ (Almeida, 1999). 
Os tratamentos foram dispostos em delineamento experimental inteiramente casualizado sob arranjo fatorial 4 x 3 (quatro proporções de sisal para três solos coletados em distintas distância da sede da antiga Companhia Brasileira de Chumbo), com cinco repetições, totalizando 60 unidades experimentais. As quatro proporções do resíduo de sisal:solo (v/v, \%) foram as seguintes: 0:100; 30:70; 50:50 e 70:30.

O solo utilizado como substrato para avaliação do desenvolvimento inicial do feijão-caupi foi coletado no município de Santo Amaro (BA), em três pontos nas proximidades da antiga Companhia Brasileira de Chumbo (COBRAC). Coletou-se o solo na profundidade de $0,20 \mathrm{~m}$, os pontos de coleta corresponderam a distância da fábrica de 50, 100 e 150 m. O solo da área original, sem a intervenção da atividade de mineração, é caracterizado como Vertissolo, apresentando classe textural entre argilosa e muito argilosa (Souza, 2014).

As amostras foram secas ao ar e em seguida passadas em peneira de malha de $4 \mathrm{~mm}$ para compor os substratos. Posteriormente foi realizada a análise química através da metodologia descrita em EMBRAPA(1997), o resultado encontra-se disposto na Tabela 1.
O resíduo de sisal, utilizado como substrato, foi coletado na Região Sisaleira da Bahia, no município de Valente. Este resíduo foi oriundo do processo de extração das fibras de sisal de um agricultor familiar da região. As sementes crioulas de feijão-caupi foram cedidas por um agricultor familiar da região do Recôncavo da Bahia, estas foram semeadas em sacos plásticos com capacidade para $1 \mathrm{~kg}$. Utilizaram-se três sementes por saco e o desbaste foi realizado aos dez dias após a emergência (DAE), deixando-se uma planta por saco. Os sacos foram irrigados três vezes por semana, para manter a umidade do solo próxima à capacidade de campo. As variáveis analisadas foram: clorofila total $(a+b)(\mathrm{CT})$, número de nódulos $(\mathrm{NN})$, área foliar ( $\mathrm{AF})$, massa seca da parte aérea (MSPA), massa seca da raiz (MSR) e massa seca total (MST).

Aos 55 DAE, correspondente ao estágio fenológico da floração, realizou-se a leitura de clorofila $a$ e $b$ no terço mediano em três folhas por planta, por soma obtevese a clorofila total, utilizou-se um medidor eletrônico Falker modelo CFL1030. Em seguida as plantas foram coletadas e as raízes separadas da parte aérea na base do caule. As raízes foram lavadas em água corrente e os nódulos foram destacados e contados. Foi realizada

Tabela 1 - Caracterização química dos solos coletados na antiga sede da Companhia Brasileira de Chumbo (COBRAC)

\begin{tabular}{|c|c|c|c|}
\hline Atributos químicos & Solo $50 \mathrm{~m}$ & Solo $100 \mathrm{~m}$ & Solo $150 \mathrm{~m}$ \\
\hline $\mathrm{pH}\left(\mathrm{H}_{2} \mathrm{O}\right)$ & 5,0 & 5,3 & 7,0 \\
\hline $\mathrm{Ca}^{2+}\left(\mathrm{cmol}_{\mathrm{c}} \mathrm{dm}^{-3}\right)$ & 21,90 & 23,80 & 35,60 \\
\hline $\mathrm{Mg}^{2+}\left(\mathrm{cmol}_{\mathrm{c}}^{\mathrm{c}} \mathrm{dm}^{-3}\right)$ & 8,40 & 10,50 & 3,90 \\
\hline $\mathrm{K}\left(\mathrm{mg} \mathrm{dm}^{-3}\right)$ & 150,00 & 178,00 & 56,00 \\
\hline$P\left(\mathrm{mg} \mathrm{dm}^{-3}\right)$ & 11,05 & 3,21 & 3,84 \\
\hline P-rem $\left(\mathrm{mg} \mathrm{L}^{-1}\right)$ & 14,60 & 5,63 & 18,88 \\
\hline $\mathrm{Al}^{3+}\left(\mathrm{cmol}_{\mathrm{c}} \mathrm{dm}^{-3}\right)$ & 0,20 & 0,40 & 0,00 \\
\hline $\mathrm{H}+\mathrm{Al}\left(\mathrm{cmol}_{\mathrm{c}} \mathrm{dm}^{-3}\right)$ & 4,99 & 4,37 & 0,76 \\
\hline $\mathrm{T}\left(\mathrm{cmol}_{\mathrm{c}} \mathrm{dm}^{-3}\right)$ & 35,67 & 39,13 & 40,40 \\
\hline $\mathrm{t}\left(\mathrm{cmol}_{\mathrm{c}} \mathrm{cm}^{-3}\right)$ & 30,88 & 35,16 & 39,64 \\
\hline $\mathrm{S}\left(\mathrm{mg} \mathrm{dm}^{-3}\right)$ & 26,57 & 43,65 & 22,46 \\
\hline $\mathrm{Cu}^{2+}\left(\mathrm{mg} \mathrm{dm}^{-3}\right)$ & 11,15 & 5,62 & 0,88 \\
\hline $\mathrm{Mn}^{2+}\left(\mathrm{mg} \mathrm{dm}{ }^{-3}\right)$ & 115,15 & 321,84 & 46,29 \\
\hline $\mathrm{Zn}^{2+}\left(\mathrm{mg} \mathrm{dm}^{-3}\right)$ & 110,14 & 73,33 & 34,89 \\
\hline $\mathrm{Fe}^{2+}\left(\mathrm{mg} \mathrm{dm}^{-3}\right)$ & 188,72 & 88,55 & 4,07 \\
\hline $\mathrm{B}\left(\mathrm{mg} \mathrm{dm}^{-3}\right)$ & 0,13 & 0,15 & 0,10 \\
\hline $\mathrm{Pb}\left(\mathrm{mg} \mathrm{dm} \mathrm{dm}^{-3}\right)$ & 176,55 & 5,90 & 3,54 \\
\hline $\mathrm{Cd}\left(\mathrm{mg} \mathrm{dm}^{-3}\right)$ & 14,74 & 0,02 & 0,81 \\
\hline$V(\%)$ & 86,02 & 88,82 & 98,13 \\
\hline $\mathrm{SB}\left(\mathrm{cmol}_{\mathrm{c}} \mathrm{dm}^{-3}\right)$ & 30,68 & 34,76 & 39,64 \\
\hline$m(\%)$ & 0,65 & 1,14 & 0,00 \\
\hline $\mathrm{MO}\left(\mathrm{dag} \mathrm{kg}^{-1}\right)$ & 3,99 & 3,14 & 1,07 \\
\hline
\end{tabular}


a análise de área foliar com a utilização de medidor portátil de área foliar ADC modelo AM-300. A parte área e as raízes foram secas em estufa a $65^{\circ} \mathrm{C}$ por 72 horas, posteriormente pesadas em balança analítica e a MST foi obtida pela soma da MSPA e da MSR.

Os resultados foram submetidos à análise de variância e quando significativos utilizou-se o teste de Tukey $5 \%$ para os solos (tratamentos qualitativos) e de regressão polinomial para as proporções de sisal (tratamentos quantitativos). O programa estatístico utilizado foi o SISVAR 5.4 (Ferreira, 2014).

\section{RESULTADOS E DISCUSSÃO}

Não houve interação entre o solo e as proporções de resíduo de sisal para as variáveis: número de nódulos $(\mathrm{NN})$, área foliar (AF), massa seca da parte aérea (MSPA), massa seca da raiz (MSR) e massa seca total (MST). Houve efeito significativo da interação entre os solos e as proporções de resíduo de sisal para a variável clorofila total (CT) (Tabela 2).

As plantas nodularam em todos os tratamentos, independente dos teores de $\mathrm{Pb}$ e demais metais. Verificaram-se efeitos individuais dos solos e do resíduo de sisal para o NN. As plantas cultivadas no solo coletado a $150 \mathrm{~m}$ da COBRAC apresentaram média de 4,9 nódulos plantas $^{-1}$, superior aos demais $(\mathrm{P}<0,05)$ (Tabela 3$)$.

O máximo $\mathrm{NN}$ foi de 5 nódulos planta ${ }^{-1}$ na proporção média de 80:20 de solo:sisal (Figura 1A). Para a CT houve efeito quadrático das doses de sisal, obtendo máxima média $(52,8$ e 49,7$)$ nas proporções estimadas de 69:31 e 58:42 (solo:sisal), respectivamente para os solo coletados a 50 e $100 \mathrm{~m}$ (Figura 1B). Para o solo coletado a 150 m não houve efeito significativo $(\mathrm{P}>0,05)$.

Os dados obtidos para o NN na presente pesquisa confirmaram a capacidade que o feijão-caupi possui de nodular com bactérias fixadoras do $\mathrm{N}_{2}$ atmosférico (Melloni et al., 2006; Chagas Júnior et al., 2010; Medeiros et al., 2009).

Alguns trabalhos foram importantes para o conhecimento do número de nódulos de feijão-caupi por planta em diferentes tipos de solo, região e período de avaliação. Xavier et al. (2008), encontraram em condições de campo média 8 nódulos planta ${ }^{-1}$ para o tratamento testemunha sem inoculação e sem adubação nitrogenada aos 36 dias após a emergência no estado do Piauí. Costa et al. (2011), encontraram 10,8 nódulos planta $^{-1}$ em média no tratamento testemunha sem N aos 45 dias após a semeadura no estado do Piauí em condições de campo. Melo \& Zilli (2009), encontraram 1,2 nódulos em média por plantas cultivadas em vaso no tratamento sem $\mathrm{N}$ aos 55 dias após a emergência das plantas no estado de Roraima.

Diversos fatores podem afetar a simbiose entre planta e bactéria interferindo na nodulação e número de nódulos por planta, entre estes destacam-se a acidez do solo (Macció et al., 2002) e a disponibilidade de nutrientes (Ferreira et al., 2009). Evidencia-se que no presente estudo as plantas de feijão-caupi, ainda que cultivadas em solos de mineração de chumbo e em condição de viveiro, obtiveram médias de nódulos similares a encontradas em diferentes solos e regiões, conforme citado anteriormente. Contudo, Almeida et

Tabela 2 - Resumo da análise de variância das médias dos parâmetros de avaliação do feijão-caupi (Vigna unguiculata L. Walp.) cultivado em solos de mineração de chumbo adubados com resíduo de sisal (Agave sisalana)

\begin{tabular}{|c|c|c|c|c|c|c|c|}
\hline \multirow{2}{*}{ Fonte de variação } & \multirow{2}{*}{ GL } & \multicolumn{5}{|c|}{ Quadrados médios } & \multirow[b]{2}{*}{ MST } \\
\hline & & $\mathrm{NN}$ & CLT & $\mathrm{AF}$ & MSPA & MSR & \\
\hline Solo & 2 & $10,74^{* *}$ & $42,87^{\mathrm{ns}}$ & $597899015,02^{* * *}$ & $1,67^{* *}$ & $0,06^{\mathrm{ns}}$ & $2,35^{* *}$ \\
\hline Proporção & 3 & $18,12^{* *}$ & $162,30^{* *}$ & $625217568,86^{* *}$ & $3,85^{* *}$ & $0,59^{* *}$ & $7,42^{* *}$ \\
\hline Solo*Proporção & 6 & $1,35^{\mathrm{ns}}$ & $120,09^{* *}$ & $54645887,46^{\mathrm{ns}}$ & $0,21^{\mathrm{ns}}$ & $0,11^{\mathrm{ns}}$ & $0,38^{\mathrm{ns}}$ \\
\hline Erro & 48 & 1,31 & 31,92 & 47311689,03 & 0,23 & 0,07 & 0,33 \\
\hline $\mathrm{CV}(\%)$ & & 28,14 & 11,96 & 22,36 & 20,26 & 38,64 & 18,88 \\
\hline Média & & 4,1 & 47,2 & 30756,2 & 2,376 & 0,669 & 3,045 \\
\hline
\end{tabular}

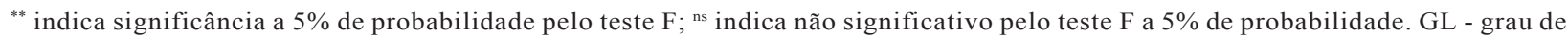
liberdade; CV - coeficiente de variação; NN - número de nódulos; CT - clorofila total; AF - área foliar; MSPA - massa seca da parte aérea; MSR - massa seca da raiz e MST - massa seca total. 
Tabela 3 - Nodulação, área foliar (AF) e fitomassa de plantas de feijão-caupi (Vigna unguiculata L. Walp.) cultivadas em solos de mineração de chumbo adubados com sisal resíduo (Agave sisalana)

\begin{tabular}{|c|c|c|c|c|c|}
\hline Tratamento* & $\mathrm{NN}$ & $\mathrm{AF}$ & MSPA & MSR & MST \\
\hline & planta $^{-1}$ & mm planta ${ }^{-1}$ & 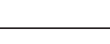 & $\mathrm{g} \mathrm{planta}^{-1}$ & \\
\hline $50 \mathrm{~m}$ & $3,8 \mathrm{~b}$ & $26506 \mathrm{~b}$ & $2,28 \mathrm{~b}$ & 0,65 a & $2,93 \mathrm{~b}$ \\
\hline $100 \mathrm{~m}$ & $3,5 \mathrm{~b}$ & $28837 \mathrm{~b}$ & $2,15 \mathrm{~b}$ & $0,63 \mathrm{a}$ & $2,77 \mathrm{~b}$ \\
\hline $150 \mathrm{~m}$ & 4,9 a & $36924 \mathrm{a}$ & $2,70 \mathrm{a}$ & $0,73 \mathrm{a}$ & 3,43 a \\
\hline Média & 4,1 & 30756 & 2,38 & 0,67 & 3,04 \\
\hline C.V. $(\%)$ & 28,1 & 22,3 & 20,26 & 38,6 & 18,9 \\
\hline
\end{tabular}

Número de nódulos (NN), massa seca da parte aérea (MSPA), massa seca da raiz (MSR) e massa seca total (MST). Médias seguidas pela mesma letra na coluna não diferem entre si pelo teste Tukey a $5 \%$ de probabilidade. $*$ Solos coletados na profundidade de $0,20 \mathrm{~m}$ que corresponderam a distância da antiga Companhia Brasileira de Chumbo (COBRAC) de 50, 100 e $150 \mathrm{~m}$.
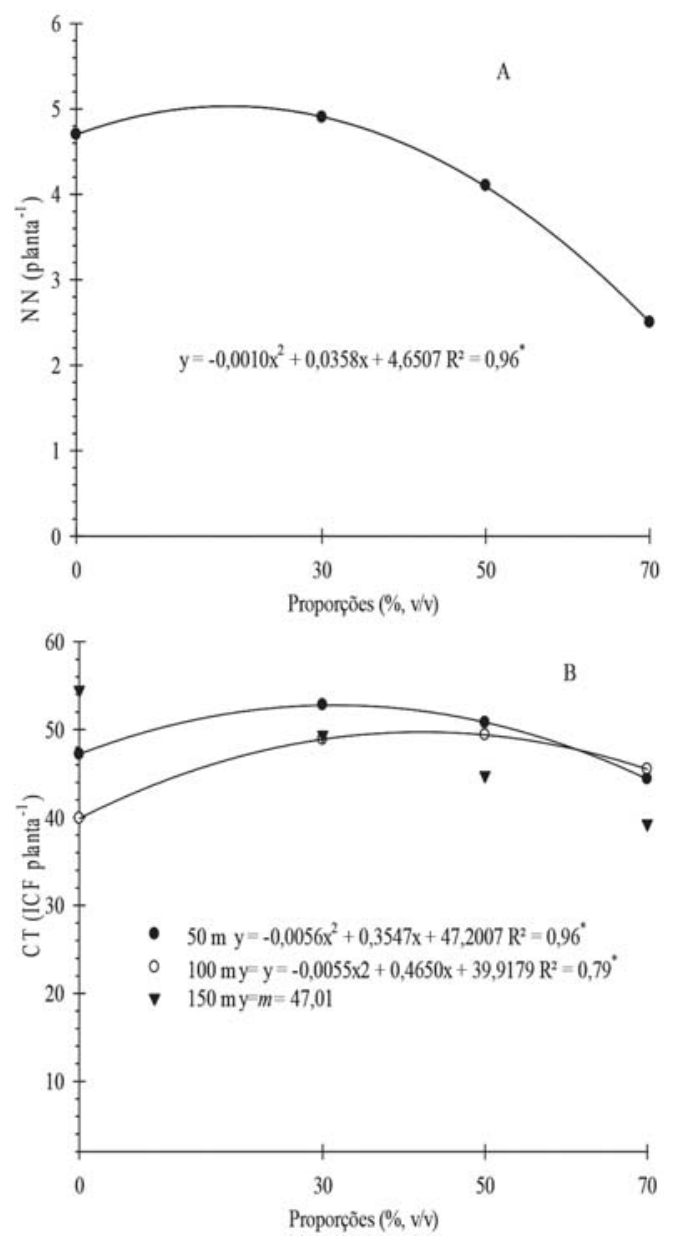

Figura 1 - (A) Número de nódulos (NN)e (B) clorofila total (CT) de plantas de feijão-caupi(Vigna unguiculata L. Walp.) cultivadas em solos de mineração de chumbo adubados com resíduo de sisal (Agave sisalana). LEGENDA: $\bullet \% 50 \mathrm{~m} ; \boldsymbol{\varpi} \% 100 \mathrm{~m} ; \boldsymbol{\nabla} 150$ $m$ de distância da sede da COBRAC. al. (2008) ao avaliarem o desenvolvimento do feijãode-porco na presença de $\mathrm{Pb}$, observaram que nenhuma das plantas formaram nódulos, até mesmo aquelas que receberam inoculação com estirpes de rizóbio.

A CT no tecido foliar tem relação direta com o teor de nitrogênio, demonstrando o papel do $\mathrm{N}$ na formação da clorofila, conforme observado por Barbosa Filho et al. (2008) em feijão comum e Silva et al. (2010) em feijão-caupi. Deste modo pode-se inferir que a clorofila pode estimar a quantidade de $\mathrm{N}$ presente nas folhas das plantas, já que o $\mathrm{N}$ faz parte da molécula de clorofila, e quanto maior a presença do mesmo, certamente maiores sínteses de clorofila. Outros resultados foram encontrados na literatura em outras plantas. Silva et al. (2013) observaram que o aumento da concentração de $\mathrm{Pb}$ resultou numa queda significativa na $\mathrm{CT}$ em plantas de girassol.

Para a AF houve efeito individual dos solos, sendo que o coletado a $150 \mathrm{~m}$ da COBRAC obteve média de $36924 \mathrm{~mm}$ planta $^{-1}$, sendo superior aos demais $(\mathrm{P}<0,05)$ (Tabela 3$)$. Em relação às proporções de sisal utilizadas observou-se um comportamento quadrático em que a maior AF da planta foi de 35354

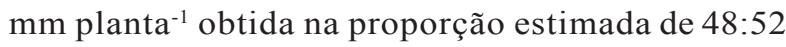
(solo:sisal) (Figura 2).

Efeito individual do tipo de solo foi verificado na MSPA, as plantas cultivadas com o solo $150 \mathrm{~m}$ de distância da COBRAC apresentaram a maior média (Tabela 3), diferindo dos demais solos $(\mathrm{P}<0,05)$. A resposta para a proporção de sisal foi quadrática, sendo a proporção média de 53:47 (solo:sisal) a que contribuiu para o ponto máximo de crescimento da planta que foi de 2,76 g planta $^{-1}$ (Figura 3a). 
Para a MSR foi observado somente efeito individual das proporções de sisal, apresentando um comportamento quadrático, sendo que a proporção média de 56:44 (solo:sisal) que proporcionou o valor

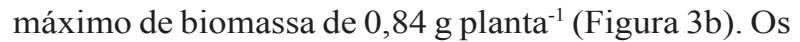
solos utilizados como substrato não diferiram entre si pelo teste Tukey $(\mathrm{P}<0,05)$ (Tabela 3$)$.

Não foi observada necrose e deformidade aparente nas raízes em função do $\mathrm{Pb}$ em plantas de feijão-caupi em nenhum dos tratamentos no presente estudo. Resultados distintos foram encontrados por Almeida et al. (2008), que ao avaliarem o desenvolvimento do feijão-de-porco (Canavalia ensiforms) na presença $\mathrm{de} \mathrm{Pb}$, as plantas apresentaram sintomas de fitotoxidade nas raízes a partir da dose de $250 \mu \mathrm{mol} \mathrm{L} \mathrm{L}^{-1}$ de $\mathrm{Pb}$. Entretanto não houve prejuízos no desenvolvimento da cultura, mostrando possuir potencial fitoextrator para $\mathrm{Pb}$. Silva et al. (2013), ao avaliarem o crescimento inicial de girassol (Helianthus annuus) em ambiente contaminado com $\mathrm{Pb}$, observaram que a aplicação do $\mathrm{Pb}$ a partir da dose $51,8 \mathrm{mg} \mathrm{L}^{-1}$ promoveu necrose nas folhas, na medida em que aumentou a dose de $\mathrm{Pb}$ em solução, aumentou o número de folhas com presença de necrose.

A MST foi influenciada, individualmente, pelo resíduo de sisal e pelo tipo de solo $(\mathrm{P}<0,05)$ utilizado

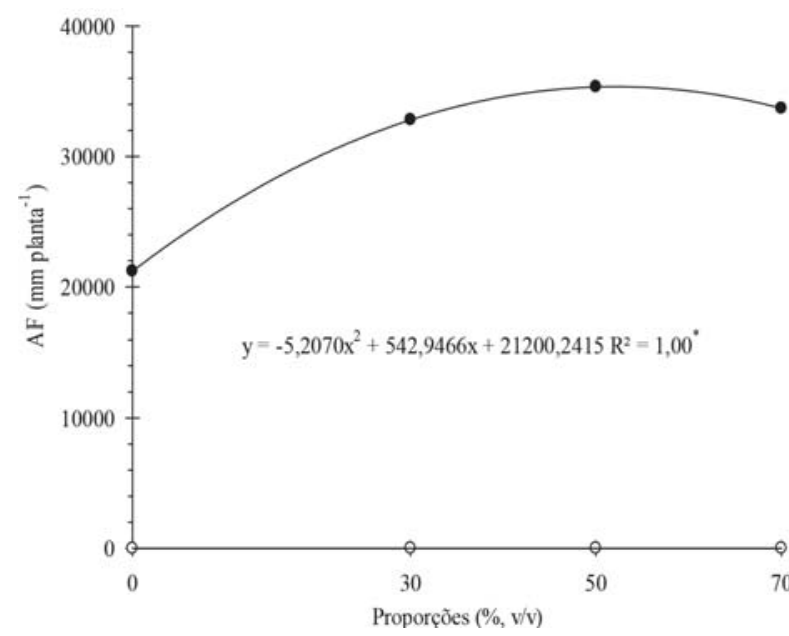

Figura 2 - Área foliar (AF) de plantas de feijão-caupi (Vigna unguiculata L. Walp.) cultivadas em solos de mineração de chumbo adubados com resíduo de sisal (Agave sisalana). para compor os substratos. As proporções do resíduo de sisal apresentaram um comportamento quadrático, em que a proporção maior produção de biomassa $(3,59$ g planta $^{-1}$ ) foi obtida na proporção estimada de 54:46 (solo:sisal) (Figura 4). As plantas cultivadas com o
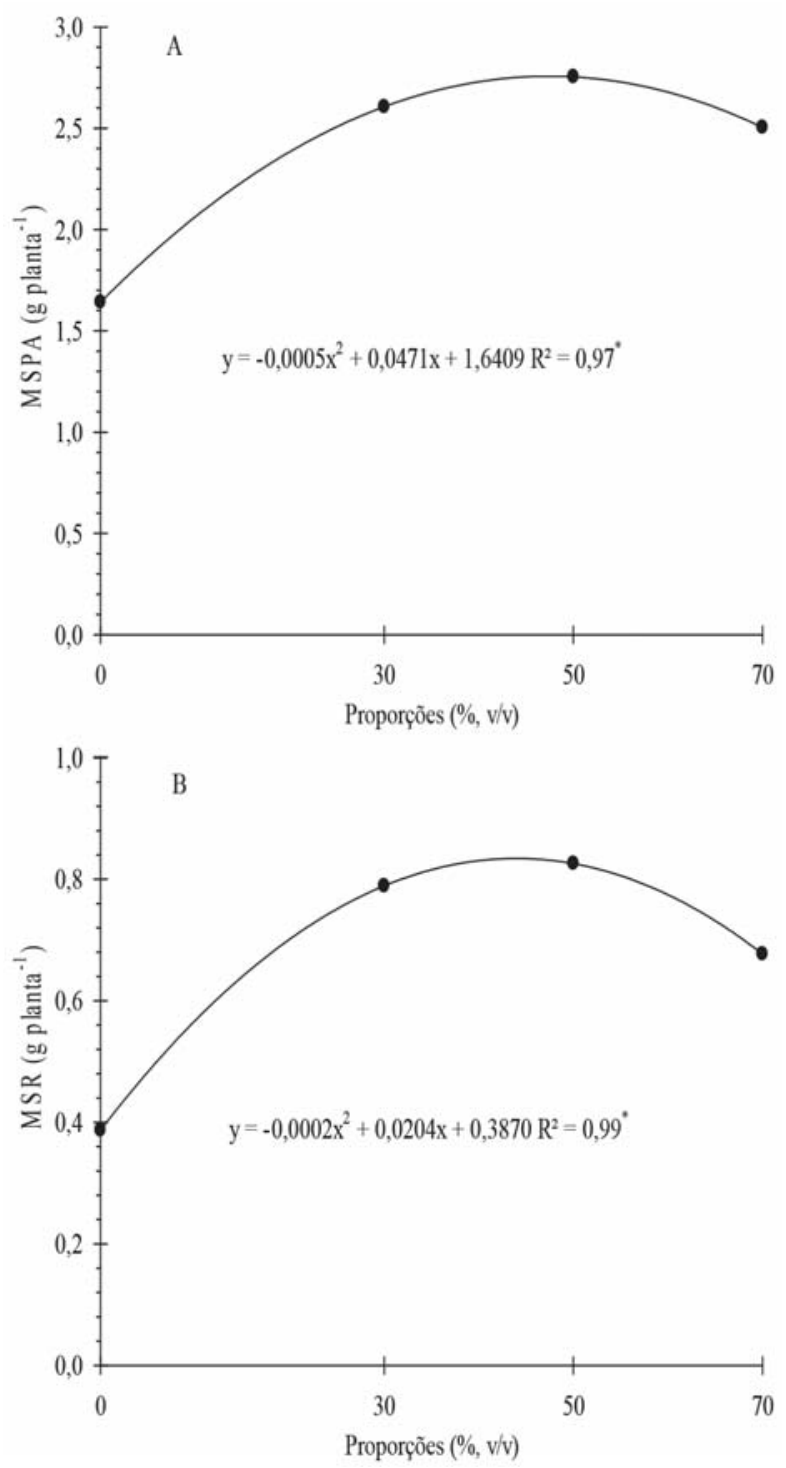

Figura 3 - (A) Matéria seca da parte aérea (MSPA) e (B) Matéria seca da raiz (MSR) de plantas de feijão-caupi (Vigna unguiculata L. Walp.) cultivadas em solos de mineração de chumbo adubados com resíduo de sisal (Agave sisalana). 


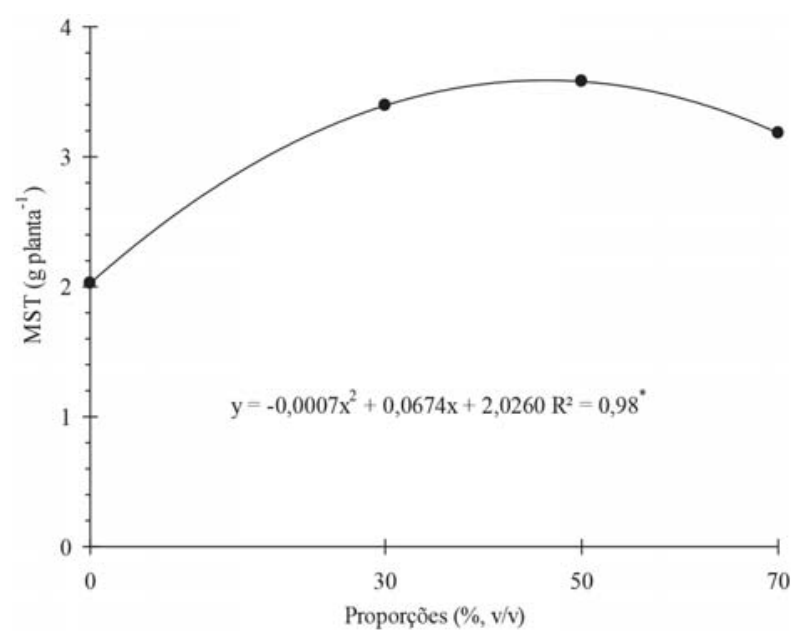

Figura 4 - Matéria seca total (MST) de plantas de feijãocaupi (Vigna unguiculata L. Walp.) cultivadas em solos de mineração de chumbo adubados com resíduo de sisal (Agave sisalana).

solo $150 \mathrm{~m}$ apresentaram a maior média, diferindo dos demais (Tabela 3).

Nas varáveis de crescimento MSPA e MST observou-se que o solo coletado a $150 \mathrm{~m}$ de distância da COBRAC obteve maiores médias em relação aos demais (Tabela 3). Isto é justificado pelo fato deste solo apresentar menores teores de metais pesados (como $\mathrm{Pb}, \mathrm{Zn}, \mathrm{Fe}$ ), conforme observado na Tabela 2. Segundo a resolução $n^{\circ} 420$ de 2009 do Conselho Nacional de Meio Ambiente (CONAMA, 2009) os valores de referência de chumbo no solo são de $180 \mathrm{mg} \mathrm{kg}^{-1}$ para solos agrícolas, $300 \mathrm{mg} \mathrm{kg}^{-1}$ para solos residenciais e $900 \mathrm{mg} \mathrm{kg}^{-1}$ para solos industriais. Observa-se que no solo coletado a $50 \mathrm{~m}$ de distância da COBRAC o valor de $\mathrm{Pb}$ encontra-se muito elevando, próximo ao do valor limite estabelecido pelo CONAMA (2009). Além do $\mathrm{Pb}$, outros metais pesados encontram-se em altas concentrações como o $\mathrm{Cu}, \mathrm{Mn}, \mathrm{Zn}$ e Fe (Tabela 2), conforme já relatado na literatura (Assunção, 2012; Magna et al., 2013).

Sabendo-se do potencial do feijão-caupi como planta-isca para captura de BNL nativas do solo, diante dos resultados encontrados são importantes futuros estudos para caracterização e isolamento de bactérias tolerantes a metais pesados no solo de mineração da antiga Companhia Brasileira de Chumbo (COBRAC). Assim, essas bactérias podem ser utilizadas para fabricação de inoculantes para culturas de leguminosas com potencial fitorremediador, constituindo-se uma alternativa mitigadora das altas concentrações de metais no solo na cidade de Santo Amaro, Bahia.

\section{CONCLUSÕES}

A proporção média de 80:20 de solo:sisal no substrato proporcionou o máximo número de nódulos em plantas de feijão-caupi cultivado em solos de mineração de chumbo.

A adição do resíduo de sisal proporcionou o aumento no índice de clorofila e na massa seca total em plantas de feijão-caupi cultivado em solos de mineração de chumbo.

\section{LITERATURACITADA}

ALMEIDA, E.L.; MARCOS, F.C.C.; SCHIAVINATO, M.A. et al. Crescimento de feijãode-porco na presença de chumbo. Bragantia, v.67, n.3, p.569-576, 2008.

ALMEIDA, O.A. Informações meteorológicas do CNP. Cruz das Almas, BA: EMBRAPA - CNPMF. 1999. 35p. (EMBRAPA - CNPMF. Documentos, 34).

ASSUNÇÃO, S.J.R. Seleção de plantas para fitorremediação de chumbo, cádmio e zinco de uma área contaminada na Bacia do Rio Subaé. 2012.100f. Dissertação (Mestrado em Solos e Qualidade de Ecossistemas) - Universidade Federal do Recôncavo da Bahia, Cruz das Almas.

BARBOSA FILHO, M.P.; COBUCCI, T.; FAGERIA, N.K. et al. Determinação da necessidade de adubação nitrogenada de cobertura no feijoeiro irrigado com auxílio do clorofilômetro portátil. Ciencia Rural, v.38, n.7, p.1843-1848, 2008

CHAGAS JUNIOR, A.F.; OLIVEIRA, L.A.; OLIVEIRA, A.N. Caracterização fenotípica de rizóbio nativos isolados de solos da Amazônia e eficiência simbiótica em feijão caupi. Acta

Scientiarum Agronomy, v.32, n.1, p.161-169, 2010. 
CONSELHO NACIONAL DE MEIO AMBIENTE. Resolução $\mathbf{n}^{\circ}$ 420, de 28 de dezembro de 2009. Dispõe sobre critérios e valores orientadores de qualidade do solo quanto à presença de substâncias químicas e estabelece diretrizes para o gerenciamento ambiental de áreas contaminadas por essas substâncias em decorrência de atividades antrópicas. Brasília, 2009. Disponível em: <http://www.mma.gov.br/ port/conama/res/res09/res42009.pdf $>$. Acesso em 05 mai. 2015.

COSTA, E.M.; NÓBREGA, R.S.A.; MARTINS, L.D.V. et al. Nodulação e produtividade de Vigna unguiculata (L.) Walp. por cepas de rizóbio em Bom Jesus, PI. Revista Ciência

Agronômica, v.42, n.1, p.1-7, 2011.

COSTA, E.M.; NÓBREGA, R.S.A.; CARVALHO, F. et al. Promoção do crescimento vegetal e diversidade genética de bactérias isoladas de nódulos de feijão-caupi. Pesquisa

Agropecuária Brasileira, v.48, p.1275-1284, 2013.

EMPRESA BRASILEIRA DE PESQUISA AGROPECUÁRIA(EMBRAPA/SCNLS) Manual de métodos de análise de solos. Rio de Janeiro, 1997. 212p.

FERREIRA, D.F. Sisvar: A guide for its bootstrap procedures in multiple comparisons. Ciência e Agrotecnologia, v.38, p.109-112, 2014.

FERREIRA, P.A.A.; SILVA, M.A.P.; CASSETARI, A. et al. Inoculação com cepas de rizóbio na cultura do feijoeiro. Ciência Rural, v.39, n.07, p.2210-2212, 2009.

JARAMILLO, P.M.D.; GUIMARÃES, A.A.; FLORENTINO, L.A. et al. Symbiotic nitrogenfixing bacterial populations trapped from soils under agroforestry systems in the Western Amazon. Scientia Agricola, v.70, p.397-404, 2013.

KEDE, M.L.F.M.; MOREIRA, J.C.; MAVROPOULOS, E. et al. Estudo do comportamento do chumbo em latossolos brasileiros tratados com fosfatos: contribuições para a remediação de sítios contaminados. Química Nova, v.31, n.3, p.379-584, 2008.
LIMA, F.S.; NASCIMENTO, C.W.A.; ACCIOLY, A.M.A. et al. Bioconcentração de chumbo e micronutrientes em hortaliças cultivadas em solo contaminado. Revista Ciência

Agronômica, v.44, n.2, p.234-241, 2013.

MACCIÓ, D.; FABRA, A.; CASTRO, S. Acidity and calcium interaction affect the growth of Bradyrhizobium sp. and the attachment to peanut roots. Soil Biology and Biochemistry, v.34, n.2, p.201-208, 2002.

MAGNA, G.A.M.; MACHADO, S.L.; PORTELLA, R.B. et al. Chumbo e cádmio detectados em alimentos vegetais e gramíneas no município de Santo AmaroBahia. Química Nova, v.36, n.7, p.989-997, 2013.

MARINHO, R.C.N.; NÓBREGA, R.S.A.; ZILLI, J.E. et al. Field performance of new cowpea cultivars inoculated with efficient nitrogen-fixing rhizobial strains in the Brazilian Semiarid. Pesquisa Agropecuária Brasileira, v.49, n.5, p.395-402, 2014.

MARRA, L.M.; SOARES, C.R.F.S.; OLIVEIRA, S.M. et al. Biological nitrogen fixation and phosphate solubilization by bacteria isolated from tropical soils. Plant and Soil, v.357, n.1, p.289-307, 2012.

MARTIN, A.R.; MARTINS, M.A.; MATTOSO, L.H. et al. Caracterização química e estrutural de fibra de sisal da variedade Agave sisalana.

Polímeros: Ciência e Tecnologia, v.19, n.1, p.40-46, 2009.

MARTINS, C.A.S.; NOGUEIRA, N.O.; RIBEIRO, P.H. et al. A dinâmica de metais-traço no solo. Revista Brasileira de Agrociência, v.17, n.3/4, p.383-391, 2011.

MEDEIROS, E.V.; MARTINS, C.M.; LIMA, J.A.M. et al. Diversidade morfológica de rizóbios isolados de caupi cultivado em solos do Estado do Rio Grande do Norte solos do Estado do Rio Grande do Norte. Acta Scientiarum Agronomy, v.31, n.3, p.529-535, 2009.

MELLONI, R.; MOREIRA, F.M.D.S.; NÓBREGA, R.S.A. et al. Eficiência e diversidade fenotípica de bactérias diazotróficas que nodulam caupi [Vigna unguiculata (L.) Walp] e feijoeiro (Phaseolus vulgaris $\mathrm{L}$.) em solos de mineração de bauxita em reabilitação. Revista Brasileira de

Ciência do Solo, v.30, n.02, p.235-246, 2006. 
MELO, S.R.D.; ZILLI, J.E. Fixação biológica de nitrogênio em cultivares de feijão-caupi recomendadas para o Estado de Roraima.

Pesquisa Agropecuária Brasileira, v.44, n.9, p.1177-1183, 2009.

\section{MOREIRA, F.M.S. Bactérias fixadoras de} nitrogênio em leguminosas. In: MOREIRA, F. M. S.; SIQUEIRA, J. O.; BRUSSAARD, L. eds. Biodiversidade do solo em ecossistemas brasileiros. Lavras, MG: UFLA, 2008. p.621- 680.

SANTOS, M.B.; SANTOS, C.Y.; ALMEIDA, M.A. et al. Efeito inibitório in vitro de extrato vegetal de Allium sativum sobre Aspergillus niger Tiegh. Revista Brasileira de Plantas Medicinais, v.12, n.1, p.13-17, 2010.

SARR, P.S.; YAMAKAWA, T.; FUJIMOTO, S. et al. Phylogenetc diversity and symbiotic effectiveness of root-nodulating bactéria associated with coypea in the South-west área of Japan. Microbes and Environments, v.24, n.2, p.105-112, 2009.

SILVA, E.F.L.; ARAÚJO, A.S.F.; SANTOS, V.B. et al. Fixação biológica do $\mathrm{N}_{2}$ em feijão-caupi sob diferentes doses e fontes de fósforo solúvel.

Bioscience Journal, v.26, p.394-402, 2010.
SILVA, P.C.C.; JESUS, F.N.; ALVES, A.C. et al. Crescimento de plantas de girassol cultivadas em ambiente contaminado por chumbo. Bioscience Journal, v.29, p.1576-1586, 2013.

SOUZA, J.P. Caracterização de solos em uma topossequência, em área contaminada por rejeitos de mineração de chumbo. 2014. 38f.

Dissertação (Mestrado em Solos e Qualidade de Ecossistemas) - Universidade Federal do Recôncavo da Bahia, Cruz das Almas.

TRANNIN, I.C.B.; MOREIRA, F.M.S.; SIQUEIRA, J.O. Crescimento e nodulação de Acacia mangium, Enterolobium contortisiliquum e Sesbania virgata em solo contaminado com metais pesados. Revista Brasileira de Ciência do Solo, v.25, n.3, p.743-753, 2001.

XAVIER, T.F.; ARAÚJO, A.S.F.; SANTOS, V.B. et al. Inoculação e adubação nitrogenada sobre a nodulação e a produtividade de grãos de feijãocaupi. Ciência Rural, v.38, n.7, p.2037-2041, 2008.

Recebido para publicação em 22/6/2017 e aprovado em 06/11/2017. 